\title{
Legal regulation of the circular economy and ecology: current issues
}

\author{
Maria Mukhlynina ${ }^{1,2^{*}}$, Natalia Mishina ${ }^{2}$, Natalia Vedysheva $^{3}$, and Ilmira Shikula ${ }^{2,4}$ \\ ${ }^{1}$ Institute of State and Law of the Russian Academy of Sciences, Znamenka str., 10, 119019 \\ Moscow, Russia \\ ${ }^{2}$ Moscow international University, Leningradsky Prospekt, 17, 125040 Moscow, Russia \\ ${ }^{3}$ Kutafin Moscow State Law University, Sadovaya-Kudrinskaya str., 9, 125993 Moscow, Russia \\ ${ }^{4}$ Moscow City University, 2nd Agricultural passage, 4, 1, 129226 Moscow, Russia
}

\begin{abstract}
The problem of legal regulation of the circular economy and ecology, sustainable management of municipal solid waste at the legal and organizational levels both in the Russian Federation and in the world is now coming to the fore and requires immediate solutions. Examining strategic planning documents and other legal acts, the authors attempted to examine current legal problems in the study area in the context of modern state of ecological policy of Russia and the implementation of circular economy, realizing the sustainable development goals of the $\mathrm{UN}$ in the environmental area. The authors suggest that a legal assessment of the possibility of transition of Russian industrial companies to a closed-loop economy is necessary, which is associated with an active approach to processing the materials of their products after the stage of use. In conclusion, a number of conclusions are drawn about the legal acts adopted in the Russian Federation and the organizational measures being implemented that contribute to solving various problems related to the sustainable development of the most important segment of the economy and the environment - the disposal and processing of waste, reducing its volume and the possibility of secondary use due to the development of the circular economy. Innovation is an important condition for this transition.
\end{abstract}

\section{Introduction}

The circular economy (CE), in contrast to the traditional linear development model, is a new regime that focuses on the reuse of resources to save money, protect the environment, and achieve economic development. In this regard, many countries have made the development of a closed-loop economy their strategy, as it has played an important role in adjusting the industrial structure, changing the way economic growth is conducted, building an ecological civilization, and finally promoting sustainable development.

Cyclicity, environmental friendliness and new technologies are the "beacons" that the economy of any country in the world needs to look up to at the present time. The outdated traditional model of the economy cannot adequately withstand the global challenges of our

*Corresponding author: muhlyninamm975@mail.ru 
time. right before our eyes, it is creating a new resource-efficient model-the circular economy. The circular economy is a new model of economy based on the renewal of resources with the involvement of the latest scientific developments of scientists, innovative projects and technologies that make the process of using natural resources almost endless.

The reorientation to a new model of socio-economic development in Russia corresponds to the trend of the developed countries of the world, which, together with the member States of the United Nations, adopted the sustainable development Goals for the period up to 2030 on September 25, 2015. There are seventeen goals and one hundred and sixty-nine tasks to be completed in the same time frame. Focusing on this international agenda, President of the Russian Federation Vladimir Putin issued a Decree on July 21, 2020 N 474 "On national development goals of the Russian Federation for the period up to 2030" set an ambitious goal - to achieve breakthrough development of the Russian Federation, increase the country's population, and improve the standard of living of citizens. The focus on creating a high-performance export - oriented sector, primarily in two sectorsmanufacturing and the agro-industrial complex, will undoubtedly put a heavy burden on the country's environment. The twelve key areas in which national projects have been developed in accordance with this decree relate to all major areas of the state's life, including the environment.The study of legal and organizational problems of legal regulation of the circular economy and ecology is reflected in the works of Vinogradova E.V., Mukhlynina M.M., Mukhlynin D.N., Solovyeva N.V., Lebedeva O.E. [1], Mukhlynina M. M., Vedyshev N.O., Solovyov N.V., Kozyrev A.A. [2], Mukhlynina M., Vedysheva N. [3], Pakhomova N.V., Richter K.K., Vetrova M.A. [4], Mukhlynin D.N. [5], Mishina N.V. [6]. However, the issues of comprehensive analysis of the legal regulation of the circular economy and ecology in the world and in the Russian Federation remain insufficiently developed.

\section{Methods}

Methodological basis of research was made following General scientific methods: analysis and synthesis to analyze the existing theoretical and methodological approaches, regulations and scientific research of circular economy and ecology; structural and logical methods of systematization of the factors influencing the implementation of circular economy and ecology. The method of factor analysis was used to determine the impact of various factors on the level of implementation of the state policy of the Russian Federation in the sphere of circular economy and ecology, as well as the degree of satisfaction of citizens with its results.

The information base of the research included legislative and regulatory acts, materials of state and local authorities, scientific publications of Russian and foreign researchers on the problems of improving the system of compensation for environmental damage [7].

The paper also uses the citation method as a method of argumentation, illustration, and reference load. The authors use the comparison method to compare the features, features, and characteristics of the studied objects in order to find similarities and differences between them and to describe them. The method of generalization in its particular manifestation as a method of systematization is also used by the authors in this study.

\section{Results and discussion}

As the governments of many countries (mostly developed) have become more interested in environmental issues, we have begun to meet more conditions on environmental 
conservation, resource management, sustainability, and the economic potential of a particular place (region). As a result of this policy, we often encounter terminology such as: sustainable development, global environmental trends, green economy, ecotourism, environmental protection, regional issues, technological impact on the environment (or a new version of industrial ecology), environmental issues, social responsibility, corporate responsibility, urban sustainability, sustainable tourism, circular economy, etc. In other words, the link between biodiversity, the economy, and technological progress exists in almost all socio-economic forms.

Economic regulation of nature protection devoted to Chapter 4 of the Federal law of the Russian Federation dated 10.01.2002 № 7-FZ "On environmental protection" (hereinafter the Law on environmental protection), which is based on several constitutional principles, such as payment for use of natural resources and basic rights of every citizen to a healthy environment and to prevent violations of legislation in the field of environmental protection. The main emphasis in the articles of Chapter 4 of the law is placed on the legal regulation of payments for negative impact on the environment: goals, deadlines, rates, coefficients, control, state regulation, etc. It is gratifying that article 17 specifies options for state support in the implementation of a number of measures: the use of the best available technologies, the use of recycled water supply systems without effluents, and others. The legislator provides for the possibility of establishing other measures of state support for economic activities aimed at protecting the environment at the expense of budget funding based on the norms of Federal and regional laws. Environmental insurance is another economic and legal instrument designed, according to the Law on environmental protection, to protect the property interests of legal entities and individuals in the event of environmental risks.

The economic category of insurance protection of public production finds its material expression, according to M. M. Mukhlynina, N. O. Vedysheva, N. V. Solovyova and A. A. Kozyreva, in the insurance Fund, which is important as a measure of protection against the risk of loss of property, health and income of the population [2]. From an economic point of view, the purpose of insurance is to accumulate money paid by many policyholders and invest it in the economy.

Through economic measures, the state not only encourages increased production or other economic activities, but also their elimination, which is reflected in article 18.1 of the Law on environmental protection and concerns economic incentives to stop the production and use of ozone-depleting substances and products containing them.

One of the most pressing problems of humanity at the present time can be called overpopulation, which creates a serious threat to the future of the planet at the current level of production and consumption, as well as the existing attitude to the environment. In the 2015 UN report "world population growth Prospects", researchers defined the prospective population of the planet Earth as follows: if in $2015-7.4$ billion, by $2030-8.3$ billion, by $2050-9.7$ billion. The UN Millennium development goals have significantly improved health, living standards and consumption. New challenges lie in ensuring a decent quality of life for all people in the world with a growing population, consumption and production, but at the same time - limited areas and dwindling reserves of natural resources. In may 2018, Russia hosted the St. Petersburg international economic forum, which included discussions on the circular economy, aimed at minimizing waste in addition to efficient use of resources.

Pakhomova N.V., Richter K.K., Vetrova M.A. [4], referring to the European investment Bank, among the reasons why it is necessary to make the transition to a circular economy, allocate resource, technological, socio-economic and environmental. At the same time, the latter is given priority. In particular, we are talking about taking into account negative 
externalities that lead to significant environmental damage, including in the socio-economic sphere, which should be internalized by the circular economy [8].

Closed-loop Economics is a very young discipline that deals with the efficiency of using scarce resources. Here we can observe the relationship between the rational use of natural resources in ensuring economic growth and job creation [9]. Circular Economics appears in various fields of research.

Recently, environmental Economics has become a very popular new discipline. According to Mele et al. [10], Long et al. [11], Patterson and Glavovich [12], ecological Economics combines both doctrines: on the one hand, it examines the connections between physical problems and biological spheres, and on the other hand, it examines the processes of monetary exchange at the micro-, meso-, and macro levels of the economy. This discipline, which is the link between Economics and ecology, arose from the need to emphasize their connection, given their social, environmental, political and sustainable significance at the present time.

Perhaps the approach recently proposed by Capra and Mattei [13] in their book "the Ecology of law" may provide better guidance in this regard. In their view, in order to have a functional economy linked to the extraction of natural resources, we need to transform "legal institutions from mining machines rooted in the mechanistic functioning of private property and state power to institutions based on ecological communities" [13]. Management and regulatory enforcement through such "ecological communities" that have appropriate education on natural mining restrictions is likely to be the best way to manage a circular economy.

Agrawal's concept of the "environment" [14] draws on Foucault's seminal work on knowledge and power [15] in governance beyond conventional political institutions. Here, the role of governments is to create conditions for the acquisition of knowledge in societies. In order to develop and develop optimal solutions, Governments should discuss possible contradictions in international forums. In our view, it will be necessary to conclude agreements on resource flows at the international level that would encourage environmentally and socially responsible waste management and more environmentally and cost-effective energy transfer across borders. Undoubtedly, to facilitate such processes, some reform of international relations in the field of ecology will be required. However, such reforms are likely and possible as a broader awareness and actualization of the circular economy gradually takes root in international Affairs in the field of sustainable development.

It should be noted that the acceleration of the transition from traditional to circular economy and ecology is possible with the introduction of artificial intelligence technologies. Artificial intelligence technologies can ensure sustainable development by optimizing business processes, design, and infrastructure of the economy. The ability of artificial intelligence to adapt to the environment using machine learning methods should be used to develop new models and knowledge, as well as to develop new decision-making rules. At the same time, it is necessary to take into account the possible risks of introducing artificial intelligence technologies into public relations, ensuring an appropriate legal regime for the development, implementation and functioning of artificial intelligence and a mandatory public control procedure at the stage of introducing artificial control systems into commercial operation [6]. The effectiveness of public control mechanisms in the transition to a circular economy and ecology will depend on the consistency and complexity of legal regulation in these areas. 


\section{Conclusions}

Thus, in General, this concept is not yet widespread enough in Russia. We need a legal assessment of the possibility of transition of Russian industrial companies to a closed-cycle economy, which is associated with an active approach to processing the materials of their products after the stage of use. Innovation is an important precondition for this transition. The main problem of the existing "cradle to grave" system is the burial of valuable materials after one cycle of use. The circular economy works on a different principle "from cradle to cradle". The company manages the material flow until the material returns to the beginning of the production process by itself or is delivered by other partners, which ensures a stable supply of materials at a fairly low cost. Environmental issues need to be addressed at the product design stage, not at the last stage. Russian practice shows, on the one hand, low involvement of industrial companies in the field of waste management, but, on the other hand, they are open to environmental innovations in the future. As such innovations, artificial intelligence technologies can be developed that will speed up the process of transition to a circular economy and ecology, optimizing the infrastructure, business models, and design of the economy and ecology.

\section{References}

1. E.V. Vinogradova, M.M. Mukhlynina, D.N. Mukhlynin, N.V. Solovyeva, O.E. Lebedeva, Journal of Environmental Management and Tourism, 1(9), 144-150 (2018).

2. M. M. Mukhlynina, N. O. Vedysheva, N. V. Solovyova, A. A. Kozyreva. Insurance law in questions and answers: textbook. Khimki: AGZ of EMERCOM of Russia, 120 p. (2018).

3. M. Mukhlynina, N. Vedysheva, APEEM 2020, 05003 (2020)

4. N.V. Pakhomova, K.K. Richter, M.A. Vetrova, Bulletin Of St. Petersburg State University Economy 33(2), 45 (2017)

5. D. N. Mukhlynin, Law and law, 6, 97 (2018)

6. N.V. Mishina. Features of legal regulation of artificial intelligence as a guarantee of sustainable development of society, IFT (2020)

7. M. Mukhlynina, N. Vedysheva, APEEM 2020, 05003 (2020)

8. H.A. Saleem, Preprints 2016, 2016090040 (2016)

9. D.B. Vukovic, R. Shams, SUSTAINABILITY, 12(1), 179 (2020)

10. B.H. Mele, L.Russo, D. D’Alelio, Sustainability, 11, 4393 (2019)

11. R.D. Long, A. Charles, R.L. Stephenson, Mar. Policy, 57, 53 (2015)

12. M.G. Patterson, B.C. Glavovic, Edward Elgar Publishing: Cheltenham (2008)

13. F. Capra, U. Mattei, The Ecology of Law: Toward a Legal System in Tune with Nature and Community, 1 (2015)

14. A. Agrawal, Environmentality: Technologies of Government and the Making of Subjects (2005)

15. M. Foucault, The Government of Self and Others: Lectures at the Collège de France 1982-1983 (2010) 